\title{
THE INFLUENCE OF TITANIUM-NIOBIUM ALLOYS ON THE GROWTH OF THE OXIDE LAYER
}

\author{
Jan KrČil**, Vladimír Mára, Jana Sobotová, Stanislav Krum \\ Department of Materials Engineering, Faculty of Mechanical Engineering, Czech Technical University in \\ Prague, Karlovo náměstí 13, 12135 Prague 2, Czech Republic \\ * corresponding author: jan.krcil@fs.cvut.cz
}

\begin{abstract}
This paper discusses issues of growth of a thin oxide layer formed on the surface of titanium alloys. The oxide layer on the surface introduces a corrosion resistance and a bio-compatibility, both of which are required for medical applications. The oxide layer is a result of a spontaneous passivation, but for the practical applications it is necessary to control the growth of oxides. In present work, the oxide layer was formed on the CP Ti grade 2, Ti39Nb alloy and CP Ti grade 2 with Ti39Nb PVD coating of two different thicknesses by a thermal oxidation at $600{ }^{\circ} \mathrm{C}$ for 8 hours. After the oxidation process the oxide layer was observed by SEM.
\end{abstract}

KEYWORDS: oxide layer, TiNb, coating, biomaterials.

\section{INTRODUCTION}

Nowadays, there is a need for better bio-implants and better bio-materials. It is due to several reasons: prolonging of human life, different lifestyle and activities, formerly incurable diseases and injuries. This may lead to the repairing or replacing parts of human body. The replacement should fit perfectly, act as the integral part of the body, have long lifetime, be bio-compatible, corrosion resistant and should not be expensive [1].

There are numerous existing materials used for body replacements. Predominantly used are titanium alloys (especially Ti-6Al-4V and CP titanium) and stainless steel AISI 316L. But as the time progresses, these materials are slowly becoming obsolete. There is need for improved mechanical properties (ideally the same as human bones) and increased bio-compatibility. The new perspective group of materials is the titanium $\beta$ alloys - Ti alloys with $\beta$ structure, usually containing $\mathrm{Nb}, \mathrm{Zr}$, Ta and other elements. These show lower modulus of elasticity, higher bio-compatbility but are more expensive on the other hand [2, 4, 5].

Titanium alloys are not bio-compatible and corrosion resistant on their own. This effect is brought by oxides on the surface. Oxide layer forms on the surface of $\mathrm{Ti}$ alloys whenever the surface is in contact with air or moisture. Resulting layer is very thin (the thickness is in the range of nanometers). The layer of such thickness would not act as the sufficient barrier and it would lead to corrosion and dissolution of the base material into the human body. The easiest way to prepare applicable oxide layer is the controlled oxidation: anodic or thermal. The composition of a layer may differ due to the chemical composition of the oxidized alloy, but the main component of the oxide layers on $\mathrm{Ti}$ alloys is titanium dioxide $\left(\mathrm{TiO}_{2}\right)$. The $\mathrm{TiO}_{2}$ naturally occurs in three different modifications: anatase, rutile and brookite. The rutile structure is stable up to melting temperature (unlike the other two) and in some cases is more suitable for the human body [2, 6]. The rutile structured oxide layer can be obtained by thermal oxidation above $500{ }^{\circ} \mathrm{C}$ [2, 7, 8].

\section{EXPERIMENT}

The experiment was based on the comparison of the oxidation results on CP Ti grade 2 and TiNb alloy with 39 wt.\% of $\mathrm{Nb}$ (from now on Ti39Nb). Bulk samples and substrates for coating were prepared by grinding and polishing to mirror sheen. Afterwards, the two groups of CP Ti samples were coated by Ti39Nb (one with $2 \mu \mathrm{m}$, other with $5 \mu \mathrm{m}$ of Ti39Nb) using Flexicoat 850, Hauzer. Subsequently, the samples were oxidized.

The type of oxidation process and its parameters were based on the literature [7, 9, 10]: oxidation at temperature of $600{ }^{\circ} \mathrm{C}$ in the air atmosphere at atmospheric pressure with dwell of 8 hours in the LAC LH 30/13 furnace equipped with MT825-A regulator. The course of the oxidation was following: heating from the room temperature with speed of $7.5^{\circ} \mathrm{C} / \mathrm{min}$ up to required $600^{\circ} \mathrm{C}$. At the end of the oxidation period, the furnace was turned off and the samples were cooled down to ambient temperature. It was expected that this process would result in formation of oxide layers with good adhesion to the substrate material. The measurement of oxide layers was carried out on the cross-section of samples using the JEOL JSM $7600 \mathrm{~F}$ scanning electron microscope.

\section{Results And Discussion}

The Fig. 1 represents the cross-sections of all 4 groups of oxidized samples. The substrate material, the coating and the oxide layer are labeled in every figure.

The Fig 1a shows oxidized sample of CP Ti grade 2. The measured thickness of the oxide layer was app. $500 \mathrm{~nm}$. In the case of oxidized sample of $\mathrm{Ti} 39 \mathrm{Nb}$ 


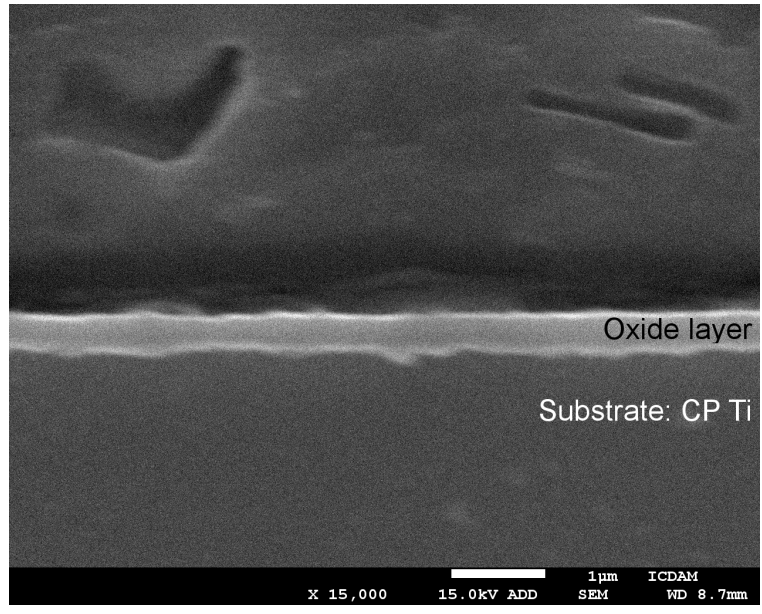

(A).

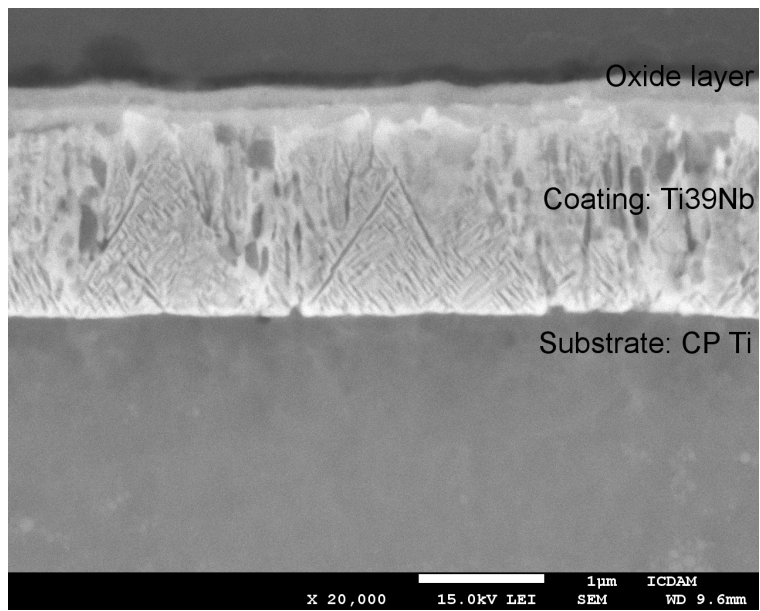

(C).

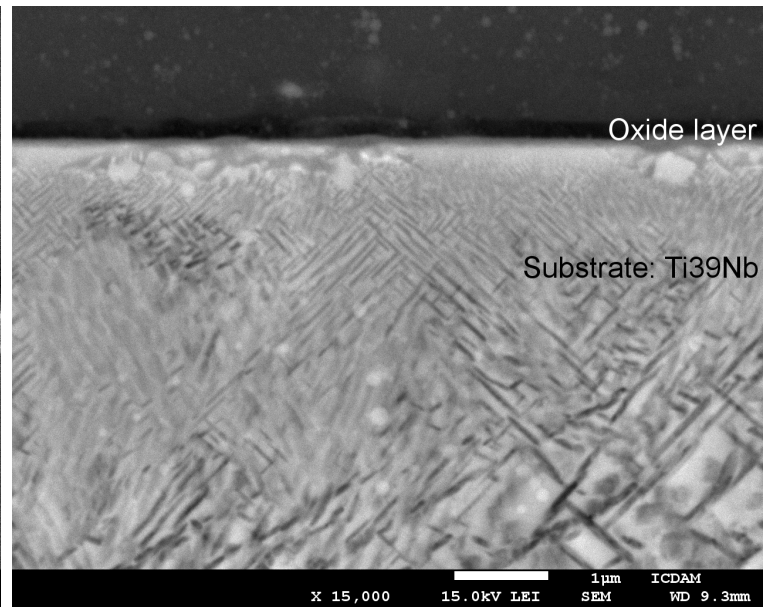

(B).

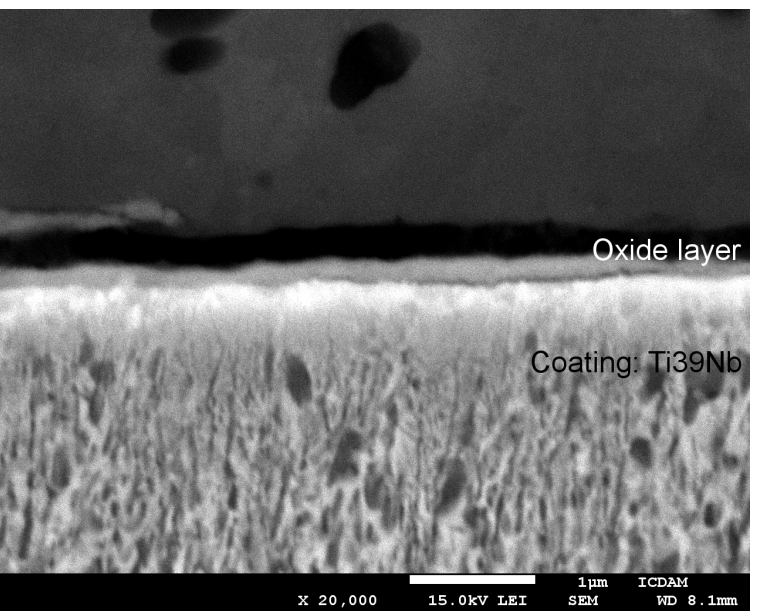

(D).

Figure 1. Cross-section of thermally oxidized $\left(600^{\circ} \mathrm{C} / 8\right.$ hours) samples: a) CP Ti grade 2, (b) Ti39Nb, (c) $\mathrm{CP} \mathrm{Ti}$ grade $2+2 \mu \mathrm{m}$ of Ti39Nb, de CP Ti grade $2+5 \mu \mathrm{m}$ of Ti39Nb.

(Fig. 1b), the oxide layer was considerably thinner than in case of the sample from $\mathrm{CP} \mathrm{Ti}$. In average, the thickness was app. $140 \mathrm{~nm}$. Samples from CP Ti with coating of Ti39Nb are in Fig. $1 \mathrm{c}$ and $1 \mathrm{~d}$. On the sample with $2 \mu \mathrm{m}$ thick coating the oxide layer with thickness ranging from $300 \mathrm{~nm}$ to $400 \mathrm{~nm}$ was found. The oxide layer thickness on the sample with $5 \mu \mathrm{m}$ coating was ranging from $200 \mathrm{~nm}$ to $300 \mathrm{~nm}$.

From the images it is evident that the oxide layers formed on all samples are compact and with relatively uniform thickness. The adhesion of the oxide layers to the substrate/coating seems to be the same for all samples. The main difference between oxide layers was found in the resulting thickness. The thickest layer was found on $\mathrm{CP} \mathrm{Ti}$ grade 2, the thinnest one on Ti39Nb. The thickness of oxide layers on Ti39Nb coatings was in between.

These preliminary results indicate that the $\mathrm{TiNb}$ alloy appears to be less vulnerable to the oxidation process than CP Ti grade 2 or that passivation process on TiNb alloy is stronger than on CP Ti grade 2 . It leads to the formation of thinner oxide layer when compared to the samples of CP Ti grade 2 which were oxidized in the same conditions and in the very same process. These findings contradict to the information found in the literature [6]. This phenomenon should be further investigated using different oxidizing conditions when compared with other materials and with other methods of the oxidation process.

\section{Conclusions}

- The oxide layer was created by the thermal oxidation on all four groups of samples and resulted in oxide layers of different thickness.

- However against the assumption, the thickness of the oxide layers showed a different trend. The oxide layer found on the samples with thicker Ti39Nb coating was thinner than on the samples with thinner Ti39Nb coating.

- The results indicate the dependence between the thickness of $\mathrm{Ti} 39 \mathrm{Nb}$ coating and the thickness of the resulting oxide layer.

- It will be further investigated how the results will differ under different oxidation conditions and with use of others method of oxidation. 


\section{ACKNOWLEDGEMENTS}

This work was supported by the Grant Agency of the Czech Republic (grant no. 15-01558S) and by the Ministry of Education, Youth and Sport of the Czech Republic, program NPU1, project No LO1207.

\section{REFERENCES}

[1] U. Kamachimudali, T. M. Sridhar, B. Raj. Corrosion of bio implants. Sadhana 28(3):601-637, 2003. DOI:10.1007/BF02706450

[2] Y. Oshida. Bioscience and Bioengineering of Titanium Materials. Elsevier, Oxford, second edition edn., 2013. DOI:http://dx.doi.org/10.1016/B978-0-44462625-7.00001-7.

[3] Biomedical Engineering, Trends in Materials Science, chap. Novel Titanium Manganese Alloys and Their Macroporous Foams for Biomedical Applications Prepared by Field Assisted Sintering. InTech, 2011. DOI:10.5772/12874

[4] I. Jirka, M. Vandrovcová, O. Frank, et al. On the role of Nb-related sites of an oxidized $\beta$-TiNb alloy surface in its interaction with osteoblast-like MG-63 cells. Materials Science and Engineering: C 33(3):1636 - 1645, 2013. DOI:http://doi.org/10.1016/j.msec.2012.12.073

[5] A. Gutiérrez, M. F. López, J. A. Jiménez, et al. Surface characterization of the oxide layer grown on
Ti-Nb-Zr and Ti-Nb-Al alloys. Surface and Interface Analysis 36(8):977-980, 2004. DOI:10.1002/sia.1816.

[6] Medical Device Materials V: Proceedings from the 2009 Materials 83 Processes for Medical Devices Conference, chap. Titanium Oxide Layer on the Surface of Anodized Dental Implants. ASM International.

[7] G. Zorn, A. Lesman, I. Gotman. Oxide formation on low modulus Ti45Nb alloy by anodic versus thermal oxidation. Surface and Coatings Technology 201(3-4):612 - 618, 2006. DOI:http://doi.org/10.1016/j.surfcoat.2005.12.009

[8] Z. Abdolldhi, A. A. Ziaee, A. Afshar. Investigation of titanium oxide layer in thermal-electrochemical anodizing of Ti6Al4V alloy. International Journal of Chemical \& Biomolecular Engineering 2(1):44, 2009.

[9] H. Jiang, M. Hirohasi, Y. Lu, H. Imanari. Effect of Nb on the high temperature oxidation of Ti-(0-50 at.\%)Al. Scripta Materialia 46(9):639 - 643, 2002. DOI:https://doi.org/10.1016/S1359-6462(02)00042-8.

[10] S. Sartale, A. Ansari, S.-J. Rezvani. Influence of Ti film thickness and oxidation temperature on $\mathrm{TiO} 2$ thin film formation via thermal oxidation of sputtered $\mathrm{Ti}$ film. Materials Science in Semiconductor Processing 16(6):2005 - 2012, 2013. DOI:https://doi.org/10.1016/j.mssp.2013.07.006 